UNIVERSITÉ DE LAUSANNE - FACULTÉ DE BIOLOGIE ET DE MÉDECINE

DÉPARTEMENT UNIVERSITAIRE D’OPHTALMOLOGIE

Service d'oculo-génétique

\title{
Risk Assessment of Recurrence in Sporadic Retinoblastoma Using a Molecular-based Algorithm
}

THÈSE

préparée sous la direction du Professeur Francis L. Munier et présentée à la Faculté de biologie et de médecine de l'Université de Lausanne pour l'obtention du grade de

\section{DOCTEUR EN MÉDECINE}

$$
\text { Par }
$$

WW

270

HOA

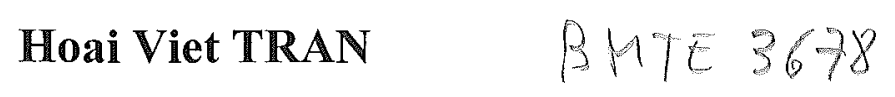

Médecin diplômé de la Confédération Suisse

Originaire de Lausanne (VD)

Lausanne

2012 


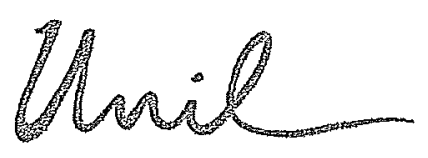

UNIL | Université de Lausanne

Faculté de biologie

et de médecine

Ecole Doctorale

Doctorat en médecine

\section{Imprimatur}

Vu le rapport présenté par le jury d'examen, composé de

Directeur de thèse Monsieur le Professeur Francis L. Munier

Co-Directeur de thèse

Expert

Monsieur le Docteur Julien Bogousslavsky

Directrice de l'Ecole Madame le Professeur Stephanie Clarke doctorale

la Commission MD de l'Ecole doctorale autorise l'impression de la thèse de

\section{Monsieur Hoai Viet Tran}

intitulée

Risk Assessment of Recurrence in Sporadic Retinoblastoma Using a Molecular-based Algorithm

Lausanne, le 18 octobre 2012

pour Le Doyen

de la Faculté de Biologie et de Médecine

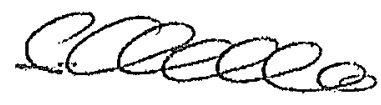

Madame le Professeur Stephanie Clarke Directrice de l'Ecole doctorale 


\section{RESUME}

Le rétinoblastome $(\mathrm{Rb})$ est une tumeur provenant des cellules rétiniennes progénitrices des photorécepteurs. C'est la tumeur pédiatrique maligne la plus fréquente avec une incidence par naissance évaluée entre $1 / 15^{\prime} 000$ et $1 / 20^{\prime} 000$. Les enfants atteints de $\mathrm{Rb}$ sont diagnostiqué dans leur grande majorité avant l'âge de 4 ans, soit le temps nécessaire à la différentiation et à la maturation des photorécepteurs et donc à la disparition de la cellule d'origine du $\mathrm{Rb}$. La survie du patient, la sauvegarde oculaire et le pronostic visuel restent excellents pour autant que le traitement ne soit pas différé. Dans sa variante non héréditaire $(60 \%)$ le $\mathrm{Rb}$ est toujours unilatéral et sporadique. Le $\mathrm{Rb}$ héréditaire de transmission dominante autosomique $(40 \%)$, se décline sous toutes les formes, familiale $(10 \%)$ ou sporadique $(30 \%)$, que l'atteinte soit unilatérale ou bilatérale.

La majorité des mutations causales sont uniques et distribuées de façon aléatoire sur la totalité du gène RB1 sans région prédisposante. La détection de ces mutations est couteuse et chronophage, tout en présentant un taux de détection relativement bas; surtout dans les cas de $\mathrm{Rb}$ sporadiques unilatéraux. Dans le but d'identifier les patients présentant un risque réel de développer un $\mathrm{Rb}$, et de réduire le nombre d'examens sous narcose requis pour le dépistage de la maladie chez les sujets à risque, nous avons développé une stratégie sensible, rapide, efficace et peu couteuse basée sur une analyse de l'haplotype intragénique. Cet algorithme prend en compte a) la perte d'hétérozygotie intratumorale du gène $\mathrm{RB} 1, \mathrm{~b})$ l'origine paternelle préférentielle des nouvelles mutations germinales et c) un risque a priori dérivé des données empiriques de Vogel. Pendant la période allant de janvier 1994 à décembre 2006, nous avons comparé l'apparition de nouveau $\mathrm{Rb}$ parmi la fratrie et la descendance de patient atteints au nombre de nouveaux 
cas attendus calculé par notre algorithme. 134 familles ont été étudiées. L'analyse moléculaire a été effectuée chez 570 personnes dont 99 patients âgés de moins de 4 ans et donc à risque de développer un $\mathrm{Rb}$. Parmi cette cohorte, nous avons observé l'apparition d'un cas de Rb, alors que les risques cumulés a posteriori calculé par notre algorithme prédisait l'apparition de 1.77 nouveau cas. Dans cette étude, nous avons pu valider notre algorithme prédisant la récurrence de $\mathrm{Rb}$ chez les parents de $1^{\mathrm{er}}$ degré de patients atteints. Cet outil devrait grandement faciliter le conseil génétique ainsi que le suivi des patients à risque de développer un $\mathrm{Rb}$, surtout dans les cas ou le séquençage direct du gène RB1 n'est pas disponible ou est resté non informatif. 


\title{
Risk assessment of recurrence in sporadic retinoblastoma using a molecular-based algorithm
}

\author{
Hoai Viet Tran ${ }^{1,2}$, Daniel F. Schorderet ${ }^{2,3,4}$, Marie-Claire Gaillard ${ }^{1}$, Aubin Balmer ${ }^{1,3}$, \\ and Francis L. Munier ${ }^{1,3}$
}
${ }^{1} J u l e s$ Gonin Eye Hospital, Lausanne, Switzerland, ${ }^{2} I R O$ - Institute for Research in Ophthalmology, Sion, Switzerland, ${ }^{3}$ Department of Ophthalmology, University of Lausanne, Switzerland, and ${ }^{4} E P F L-S w i s s$ Federal Institute of Technology, Lausanne, Switzerland

\begin{abstract}
Purpose: Most RB1 mutations are unique and distributed throughout the RB1 gene. Their detection can be time-consuming and the yield especially low in cases of conservatively-treated sporadic unilateral retinoblastoma $(\mathrm{Rb})$ patients. In order to identify patients with true risk of developing $\mathrm{Rb}$, and to reduce the number of unnecessary examinations under anesthesia in all other cases, we developed a universal sensitive, efficient and cost-effective strategy based on intragenic haplotype analysis.

Methods: This algorithm allows the calculation of the a posteriori risk of developing Rb and takes into account (a) RB1 loss of heterozygosity in tumors, (b) preferential paternal origin of new germline mutations, (c) a priori risk derived from empirical data by Vogel, and (d) disease penetrance of $90 \%$ in most cases. We report the occurrence of $\mathrm{Rb}$ in first degree relatives of patients with sporadic $\mathrm{Rb}$ who visited the Jules Gonin Eye Hospital, Lausanne, Switzerland, from January 1994 to December 2006 compared to expected new cases of Rb using our algorithm.

Results: A total of 134 families with sporadic Rb were enrolled; testing was performed in 570 individuals and 99 patients younger than 4 years old were identified. We observed one new case of Rb. Using our algorithm, the cumulated total a posteriori risk of recurrence was 1.77 .

Conclusions: This is the first time that linkage analysis has been validated to monitor the risk of recurrence in sporadic $\mathrm{Rb}$. This should be a useful tool in genetic counseling, especially when direct RB1 screening for mutations leaves a negative result or is unavailable.
\end{abstract}

Keywords: Sporadic, retinoblastoma, recurrence, linkage analysis, genetic counseling

\section{INTRODUCTION}

Retinoblastoma $(\mathrm{Rb})$ is the most common pediatric ocular malignancy and the most prevalent eye cancer around the world. ${ }^{1} \mathrm{Rb}$ originates from progenitors of retinal sensory cells, most probably along a cone lineage, ${ }^{2,3}$ with an estimated incidence between $1 / 18,000$ and $1 / 20,000$ live births. ${ }^{4,5}$ Affected children will develop Rb very early in life, during the period of cellular differentiation until the age of 4 years. $\mathrm{Rb}$ is still a mutilating, blinding and sometimes lethal disorder. There are two forms of Rb; familial and sporadic, the latter being the most widespread and accounting for more than $85 \%$ of the cases.

$\mathrm{Rb}$ was a model for Knudson's two hit hypothesis. ${ }^{6}$ In his initial hypothesis, he stated that two mutational events were required for the initiation of $\mathrm{Rb}$. Later, it was shown that these two mutational events inactivate both alleles of a single gene. Current knowledge indicates that mutations affecting both alleles of the $\mathrm{Rb}$ susceptibility gene (RB1) are a prerequisite for the development of this tumor. ${ }^{6-8}$ In most patients with sporadic unilateral $\mathrm{Rb}$, the two RB1 gene mutations that initiate tumor development are somatic events, and none are present in DNA from constitutional cells. ${ }^{9-11}$ In fact $10-15 \%$ of them carry either homogeneous or mosaic mutations (see the description of the algorithm below). Patients with sporadic bilateral or familial retinoblastoma are heterozygous for an RB1 gene mutation that was either inherited from an affected parent or that occurred de novo in parental germline cells.

Received 02 November 2010; revised 08 July 2011; accepted 17 July 2011

Correspondence: Francis Munier, MD, Jules Gonin Eye Hospital, 15, Avenue de France, 1004 Lausanne VD, Switzerland. Tel: +41216268582. Fax: +41 2162685 44, E-mail: francis.munier@fa2.ch. 
Management of affected individuals also takes into account genetic counseling to relatives at risk. Genetic counseling of sporadic $\mathrm{Rb}$ can either be based on empirical risk calculations ${ }^{12}$ or on the segregation of RB1 mutant alleles. In the former case, identification of disease recurrence relies on systematic examination under anesthesia (EUA) of all first degree relatives irrespective of their genetic predisposition from birth until 4 years of age; while in the latter, only the RB1 mutant carriers are investigated. Unfortunately, the underlying technology that leads to the oncogenic mutation is only available to limited number of patients around the world and is still expensive and time-consuming. Additionally, because the inactivating mutations are highly heterogeneous and distributed along the entire coding sequence of the gene, some $90 \%$ of sporadic unilateral $\mathrm{Rb}$ and $12-25 \%$ of sporadic bilateral Rb have undetected mutation despite all mutational screening efforts, ${ }^{13-16}$ leaving more than $50 \%$ of families without molecular diagnosis and accurate genetic counseling of the disease. This prompted us to develop and validate an algorithm based on linkage analysis in a large population at risk to improve genetic counseling and disease follow-up in comparison to classical systematic EAU in patients at risk with sporadic Rb. Thus, the primary goal of molecular testing is to identify individuals with significant risk while avoiding repeated examinations in those with minimal risk.

\section{MATERIALS AND METHODS}

\section{Patients}

All consecutive patients with uni- or bilateral sporadic $\mathrm{Rb}$ including their first degree relatives seen between January 1994 and December 2006 at the Jules Gonin Eye Hospital were enrolled. Patients were referred from several countries, mostly Switzerland, Italy, Portugal and Greece. Written informed consent was obtained from all patients and members of the family using a consent form approved by the Swiss Federal Office of Public Health (035.0003-48) for Clinical Research and following the tenets of the Declaration of Helsinki.

All patients at risk were defined as siblings or children of affected $\mathrm{Rb}$ patients younger than 4 years of age. They were followed until the age of 48 months and automatically assigned a follow-up under narcosis at $1,3,6,10,15,21,28,36$ and 42 months as customary. Occurrence of new patients with $\mathrm{Rb}$ among this population was noted and compared to the predicted number of expected cases using our algorithm.

From January 1994 to July 2003, molecular characterization of RB1 alleles was performed using intra/extragenic sequence polymorphisms such as restriction fragment length polymorphisms (RFLP), variable number of tandem repeats (VNTR) sequences, and microsatellites, as listed in Table 1. From August 2003 to December 2006, polymorphic short tandems (STR) were used as recommended by the Best Practice Guidelines of the European Molecular Genetics Quality Network (EMQN) for linkage analysis of RB1 (Table 2). ${ }^{17}$ The calculated risks obtained with our algorithm were then cumulated to allow comparison with the observed occurrence of retinoblastoma in this cohort.

\section{Molecular Testing}

\section{Hybridization to cDNA Probe}

Genomic DNA from peripheral blood leukocytes and tumoral tissue (from fresh tumors) was digested with $80 \mathrm{U}$ of HindIII. The resulting fragments were separated onto $0.8 \%$ agarose-gel, and blotted onto nylon membrane. ${ }^{18}$ The filters were hybridized overnight at $42^{\circ} \mathrm{C}$ with the $\mathrm{p} 4.95 \mathrm{BT}$ probe labeled with digoxigenin. After removal of the unbound probe, the bands were detected using a chemiluminescent substrate for alkaline phosphatase. ${ }^{19}$

\section{Analysis with Polymorphic Markers}

The polymorphic markers used in this study are shown in Tables 1 and 2. Three of the RFLPs were studied by PCR-amplification of the fragments, and the digestion of the product was electrophoresed in polyacrylamide or agarose gel and detected by silver-staining with slight modifications, or ethidium bromide. The VNTR marker is detected by Southern blotting.

The analysis of microsatellite markers is carried out by PCR amplification and electrophoresis in an automated sequencing machine. ${ }^{20}$

TABLE 1 Location of the different polymorphic markers.

\begin{tabular}{lll}
\hline Polymorphic marker & Probes & Location \\
\hline Apa I & ESD 14.I.I & ESD \\
BamHI & 123M I.8 & Intron 1 \\
Kpnl & 95HS 0.5 & Intron 4 \\
Hind III & H3-8 & Exon 4 \\
Xba I & 88R 2.5 & Intron 17 \\
Xba I (I-20 microsatellites) & 88R 2.5 & Intron 20 \\
RsaI (VNTR) & 68RS 2.0 & Intron 17 \\
Tth III I (AspI) & 35R0.6 & Intron 24 \\
\hline
\end{tabular}

TABLE 2 Polymorphic short tandems (STRs) within and linked to the retinoblastoma (RB1) gene.

\begin{tabular}{lll}
\hline Marker name & Location & Accession \\
\hline D13S161 & Centromeric to RB1 (1.1Mb) & Z16802 \\
D13S287 & Centromeric to RB1 (1.0Mb) & Z24331 \\
D13S164 & Centromeric to RB1 $(0.05 \mathrm{Mb})$ & Z16858 \\
D13S153 & RB1: intron 2 & Z16494 \\
Rb1.20 & RB1: intron 20 & \\
D13S1307 & Telomeric to RB1 $(0.25 \mathrm{Mb})$ & Z51671 \\
D13S165 & Telomeric to RB1 $(0.9 \mathrm{Mb})$ & Z16900 \\
D13S273 & Telomeric to RB1 (1.25Mb) & Z23383 \\
\hline
\end{tabular}




\section{Description of the Algorithm}

We designed an algorithm based on haplotype characterization of both RB1 alleles applicable to all families. This algorithm combines segregation analysis using RB1 polymorphic markers ${ }^{21}$ and is based on: (a) a priori risk derived from empirical data by $\operatorname{Vogel}_{r}^{22}$ (b) preferential paternal origin of new germline mutations, ${ }^{23,24}$ (c) analysis of loss of heterozygosity $(\mathrm{LOH})$ in the tumor, ${ }^{25}(\mathrm{~d})$ and disease's penetrance of $90 \%$ in most cases, ${ }^{15}$ although it can vary significantly according to the mutation's type. ${ }^{14}$

In bilateral sporadic cases of $\mathrm{Rb}$, risks have been empirically calculated by Vogel as follows: the a priori recurrence risk is $6 \%$ for siblings, whereas the a priori transmission risk is $50 \%$ for the offspring. ${ }^{22}$ If $\mathrm{LOH}$ is present in the tumor, the haplotype linked to the predisposing germline mutation can be identified. This in turn allows us to accurately predict the risk (Fig. 1A):

- $2 \times 6 \%=12 \%$ risk if the retained haplotype is passed to the sibling, versus $1 / 20,000$ (exclusion) if not.

- $2 \times 50 \%=100 \%$ risk if the retained haplotype is transmitted to offspring, versus $1 / 20,000$ (exclusion) if not.

If $\mathrm{LOH}$ is not detected or if no tumoral material is available for analysis, the risk will be modified according to inheritance of grandparental alleles (Fig. 1B):
- $2 \times 6 \%=12 \%$ risk for the sibling if the same parental alleles are transmitted; $2 \times 6 \times 90 \%=10.8 \%$ if the paternal allele is transmitted (preferential paternal origin of new germline mutations in $90 \%$ of cases, ${ }^{23} 2 \times 6 \times 10 \%=1.2 \%$ if the maternal allele is transmitted and $1 / 20,000$ if both alleles are distinct.

In unilateral sporadic $R b$, the a priori recurrence risk is $1 \%$ for siblings, whereas the a priori transmission risk is $6 \%$ for the offspring. If $\mathrm{LOH}$ is present in the tumor, the haplotype linked to the predisposing germline mutation can be identified. This in turn allows the accurate prediction of the risk (Fig. 1C):

- $2 \times 1 \%=2 \%$ risk if the retained haplotype is passed to the sibling, versus $1 / 20,000$ (exclusion) if not.

- $2 \times 6 \%=12 \%$ risk if the retained haplotype is transmitted to offspring, versus $1 / 20,000$ (exclusion) if not.

If $\mathrm{LOH}$ is not detected or if no tumoral material is available for analysis, the risk will be modified according to inheritance of grandparental alleles (Fig. 1D). In unilateral $\mathrm{Rb}$, the probability of a de-novo event occurring preferentially in the paternal germline is lower than the $90 \%$ reported in bilateral cases. An estimate of this probability can be derived from the study of Schüler. ${ }^{24}$ This study found that $54 \%$ of constitutional
A

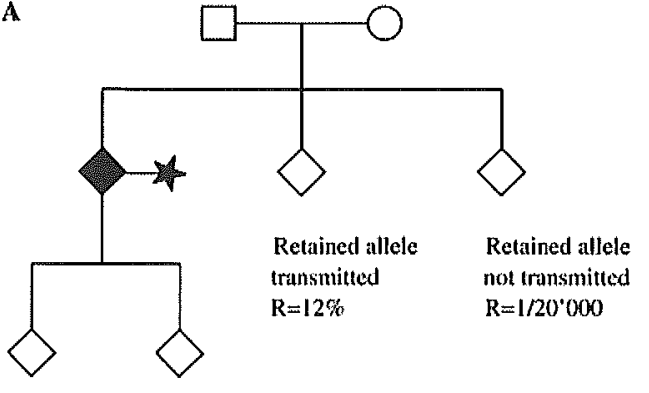

Retained allele Retained allele transmilted nol transmitted $\mathrm{R}=100 \% \quad \mathrm{R}=1 / 20^{\prime} 000$

C

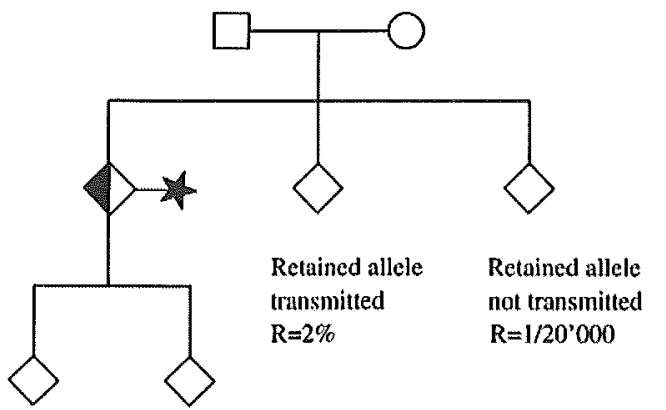

Retained allele Retained allele transmitted not transmitted $\mathrm{R}=12 \% \quad \mathrm{R}=1 / 20 \% 00$
B

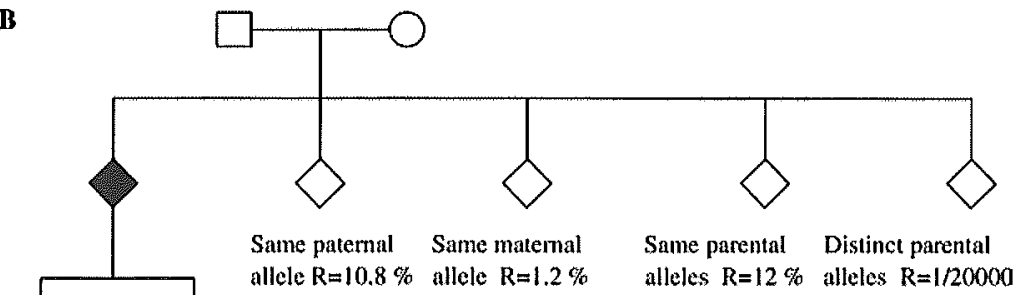
alleles $\mathrm{R}=12 \%$ alleles $\mathrm{R}=1 / 20000$

FIGURE 1 (A) Presence of loss of heterozygosity (LOH). Modification of risk in offspring (a priori risk $=50 \%$ ) and in siblings (a priori risk $=6 \%$ ) of bilaterally affected proband. (B) Absence of LOH. Modification of risk in offspring (a priori risk $=50 \%$ ) and in siblings (a priori risk $=6 \%$ ) of bilaterally affected proband. (C) Presence of $\mathrm{LOH}$. Modification of risk in offspring (a priori risk $=6 \%$ ) and in siblings (a priori risk $=1 \%$ ) of unilaterally affected proband. (D) Absence of $\mathrm{LOH}$. Modification of risk in offspring (a priori risk $=6 \%$ ) and in siblings (a priori risk $=1 \%$ ) of unilaterally affected proband. 
RB1 mutations in sporadic unilateral Rb were de novo, $29 \%$ mosaics in nature, and $17 \%$ transmitted from an unaffected parent (incomplete penetrance, two from the father and two from the mother). Therefore, the preferential paternal origin in cases of sporadic unilaterally affected patients can be estimated at $90 \% \times 54+50 \% \times 46=72 \%$ [ $90 \%$ (preferential paternal origin) of $54 \%$ (de novo mutants) + half (absence of preferential paternal origin) of $46 \%$ (mosaic and transmitted mutants)]:

- $2 \times 1 \%=2 \%$ risk if the same parental alleles are transmitted to the sibling, $2 \times 1 \times 72 \%=1.4 \%$ if the paternal allele is transmitted, $2 \times 1 \times 28 \%=0.6 \%$ if the maternal allele is transmitted and $1 / 20,000$ if both alleles are distinct.

- $2 \times 6 \times 72 \%=8.6 \%$ risk in case of inheritance of the grandpaternal haplotype in offspring, versus $2 \times 6 \times 28 \%=3.4 \%$ for the grandmaternal.

Finally the new modified calculated risk of $\mathrm{Rb}^{\prime} \mathrm{s}$ recurrence was adjusted to a penetrance of $90 \% .{ }^{15}$

The siblings and offspring of affected patients were then classified into two categories: (a) low-risk $(\leq 1.08$ $\%$, and (b) significant-risk (>1.08\%).

\section{RESULTS}

A total of 304 kindreds with sporadic $\mathrm{Rb}$ were enrolled and analyzed. Out of these 304 index patients, 134 had first degree relatives and were included. Seventy-nine $(59 \%) \mathrm{Rb}$ patients were unilateral and $55(41 \%)$ bilateral. Linkage analysis was based on the segregation of the RB1 allele in a total of 570 individuals. There were 168 first degree relatives of the index patient. Eighty-four out of 146 siblings, 15 out of 22 offspring who were younger than 48 months of age at the time of the linkage analysis and older than 48 months of age by December 2006, were enrolled. Mean age was $26.9 \pm 17.2$ months (range from birth to 47 months of age). Mean follow up time was of $60.8 \pm 15.7$ months.

\section{Classical Clinical Follow-up}

During this time, one new case of $\mathrm{Rb}$ was diagnosed from among the sibling's group at 8 months of age; from a significant-risk relative $\mathrm{Rb}^{\mathrm{s}} \mathrm{s}$ recurrence of $1.4 \times 90 \%=1.26 \%$ upon our algorithm, 6 months after the first examination and linkage analysis. It was a unilateral $\mathrm{Rb}$ due to a $\mathrm{R} 255 \mathrm{X}$ mutation, stage $\mathrm{C}$ ( $\mathrm{ABC}$ classification) that was successfully cured by conservative therapy consisting of chemo-, thermo-, and cryo-therapy without radiotherapy. The remaining patients were followed until the age of 4 years and did not develop $\mathrm{Rb}$. All the patients $(n=69)$ older than 4 years were also examined clinically and none of them had $\mathrm{Rb}$.
TABLE 3 New cumulated calculated recurrence risk of retinoblastoma.

\begin{tabular}{lccc}
$\begin{array}{l}\text { Number of } \\
\text { patients }\end{array}$ & Low risk & $\begin{array}{c}\text { Significant } \\
\text { risk }\end{array}$ & $\begin{array}{c}\text { Cumulated } \\
\text { calculated risk (\%) }\end{array}$ \\
\hline Siblings & 61 & 23 & 116.2 \\
Offspring & 8 & 7 & 61.3 \\
\hline
\end{tabular}

\section{Expected Occurrence of New Patients with Rb using our Algorithm}

Linkage analysis was informative in $129(96 \%)$ families. Molecular analysis of tumor tissue identified $23 \mathrm{LOH}$ out of $38(61 \%)$. Sixty-one of these siblings were classified as low-risk of which 21 were at no risk given the inheritance of an entirely different haplotype than the proband and 23 patients were considered at significant risk.

Eight of 15 offspring were at minimal risk of which one was at no risk. Seven patients were of significant risk. The data are summarized in Table 3.

Applying our algorithm to this cohort of patients, we expected 1.77 new declared cases of $\mathrm{Rb}$ (cumulated risk of recurrence: 1.162 for the siblings group and 0.613 for the offspring) during the pre-defined follow-up period. It should be noted that none of the patients with a different haplotype to the index patient developed $\mathrm{Rb}$ and that the new $\mathrm{Rb}$ patient occurred in the group at significant risk.

\section{DISCUSSION}

Retinoblastoma is a malignant tumor that originates from progenitors of retinal sensory cells. Affected children will therefore develop $\mathrm{Rb}$ very early in life, during the period of cellular maturation. In contrast, $\mathrm{Rb}$ is extremely rare in adults, where it sometimes arises from retinoma, a related benign lesion.

Survival rate and prevention of blindness in $\mathrm{Rb}$ patients depend on accurate and early diagnosis. If $\mathrm{Rb}$ is newly diagnosed in a family, examination of the retina is mandatory in all relatives at risk to exclude the presence of retinal tumor. Genetic counseling is required to identify relatives with an increased risk. If relatives at risk are still in early childhood, repeated EUAs are mandatory. Therefore, the primary goal of molecular testing is to identify high-risk individuals while avoiding repeated examinations (a total of nine EUAs is necessary to cover the period of potential retinal oncogenesis). Classically, genetic counseling of families with sporadic $\mathrm{Rb}$ has been based on a priori risk derived from the compilation of empiric data. ${ }^{22}$ The a priori risk of recurrence for siblings of sporadic bilateral $\mathrm{Rb}$ patients is $6 \%$ and $50 \%$ for offspring. In sporadic unilateral $\mathrm{Rb}$, these risks are $1 \%$ and $6 \%$ respectively. All patients at risk are then placed under a rigorous program of ophthalmoscopic EUA, despite the fact that only a fraction of them has inherited the $R b$ 
predisposition. To overcome the genetic burden in relatives of index $\mathrm{Rb}$ patients, it has been proposed more recently to screen directly for the presence of the disease-causing RB1 mutation. Noorani demonstrated that identification of the oncogenic mutation is cost-effective when compared to conventional screening consisting of repeated EUAs. ${ }^{13}$ However, their study was based on molecular scanning of the $180-\mathrm{Kb}$ RB1 gene, which is hampered by a low yield of only $40-45 \%(80-90 \%$ in bilateral cases and $10-15 \%$ in unilateral cases). In other words, a significant proportion of families are left without molecular diagnosis. This suggests that, nowadays, no single methodology will be fully sensitive, accurate and economic.

In the current study, an algorithm based on linkage analysis identified patients with true risk, except in situations where a sporadic unilateral $\mathrm{Rb}$ patient is a low proportion mosaic for a large RB1 gene deletion. In such a case the risk would be overestimated in the sibling, whereas the risk prediction in the offspring would tend towards either overestimation or loss of informativity. This strategy is efficient (informative in $96 \%$ of the families) and can be universally applied. More importantly, the expected recurrence risk of $\mathrm{Rb}$ in relatives was in accordance with the natural observed recurrence rate in our cohort without false negative cases. Applying our algorithm, we would have been able to avoid unnecessary EUA surveillance in 69 of $99(69.7 \%)$ patients, with a total of 362 EUAs circumvented. Therefore patients at significant risk should be automatically assigned to a follow-up under narcosis until 4 years of age, although, Abramson reported that the majority of the $\mathrm{Rb}$ is diagnosed before the age of 28 months. ${ }^{26}$ While in minimalrisk patients, this heavy surveillance can be replaced by a regular ophthalmoscopy without anaesthesia.

RFLP and VNTR analysis are less used and our institution has been primarily proceeding with direct mutation screening since 2006. However, when necessary, we are using polymorphic short tandems (STR) as recommended by the Best Practice Guidelines of the European Molecular Genetics Quality Network (EMQN) for indirect testing of RB1. ${ }^{17}$ This algorithm represents a good alternative when mutational screening failed to identify the disease-causing mutation. It is also a cost-effective approach in centers with limited financial resources. In addition, linkage analysis has never been validated for the detection of risk recurrence in sporadic cases of $\mathrm{Rb}$ and the present algorithm proved to be reliable in a long-term follow up to modify the a priori risk of $\mathrm{Rb}$ transmission.

\section{ACKNOWLEDGMENTS}

Declaration of interest: The authors report no conflicts of interest. The authors alone are responsible for the content and writing of the paper.

\section{REFERENCES}

1. Kivelä T. The epidemiological challenge of the most frequent eye cancer: retinoblastoma, an issue of birth and death. Br J Ophthalmol 2009;93:1129-1131.

2. Munier FL, Balmer A, van Melle G, Gailloud C. Radial asymmetry in the topography of retinoblastoma. Clues to the cell of origin. Ophthalmic Genet 1994;15:101-106.

3. $\mathrm{Xu} X \mathrm{~L}$, Fang $\mathrm{Y}$, Lee TC, Forrest D, Gregory-Evans $\mathrm{C}$, Almeida D, Liu A, Jhanwar SC, Abramson DH, Cobrinik D. Retinoblastoma has properties of a cone precursor tumor and depends upon cone-specific MDM2 signaling. Cell 2009;137:1018-1031.

4. Seregard S, Lundell G, Svedberg H, Kivelä T. Incidence of retinoblastoma from 1958 to 1998 in Northern Europe: advantages of birth cohort analysis. Ophthalmology 2004;111:1228-1232.

5. Broaddus $\mathrm{E}$, Topham $\mathrm{A}$, Singh AD. Incidence of retinoblastoma in the USA: 1975-2004. Br J Ophthalmol 2009;93:21-23.

6. Knudson AG. Mutation and cancer: statistical study of retinoblastoma. Proc Natl Acad Sci USA 1971;68:820-823.

7. Cavenee WK, Dryja TP, Phillips RA, Benedict WF, Godbout R, Gallie BL, Murphree AL, Strong LC, White RL. Expression of recessive alleles by chromosomal mechanisms in retinoblastoma. Nature 1983;305:779-784.

8. Friend SH, Bernards R, Rogelj S, Weinberg RA, Rapaport JM, Albert DM, Dryja TP. A human DNA segment with properties of the gene that predisposes to retinoblastoma and osteosarcoma. Nature 1986;323:643-646.

9. Shimizu T, Toguchida J, Kato MV, Kaneko A, Ishizaki K, Sasaki MS. Detection of mutations of the RB1 gene in retinoblastoma patients by using exon-by-exon PCR-SSCP analysis. Am J Hum Genet 1994;54:793-800.

10. Lohmann, DR, Brandt B, Passarge E, Horsthemke B. [Molecular genetics and diagnosis of retinoblastoma. Significance for ophthalmologic practice.] Ophthalmologe 1997;94:263-267

11. Klutz M, Horsthemke B, Lohmann DR. RB1 gene mutations in peripheral blood DNA of patients with isolated unilateral retinoblastoma. Am J Hum Genet 1999;64:667-678.

12. Draper GJ, Sanders BM, Brownbill PA, Hawkins MM. Patterns of risk of hereditary retinoblastoma and applications to genetic counselling. Br J Cancer 1992;66:211-219.

13. Noorani HZ, Khan HN, Gallie BL, Detsky AS. Cost comparison of molecular versus conventional screening of relatives at risk for retinoblastoma. Am J Hum Genet 1996;59:301-307.

14. Harbour JW. Overview of RB gene mutations in patients with retinoblastoma. Implications for clinical genetic screening. Ophthalmology 1998;105:1442-1447.

15. Lohmann DR. RB1 gene mutations in retinoblastoma. Hum Mutat 1999;14:283-288.

16. Richter S, Vandezande K, Chen N, Zhang K, Sutherland J, Anderson J, Han L, Panton R, Branco P, Gallie B. Sensitive and efficient detection of RB1 gene mutations enhances care for families with retinoblastoma. Am J Hum Genet 2003;72:253-269.

17. Lohmann D, Scheffer H, Gallie B. Best Practice Guideline for Molecular Analysis of Retinoblastoma. European Molecular Genetics Quality Network. 2002;SMT4-CT99-7515.

18. Southern EM. Detection of specific sequences among DNA fragments separated by gel electrophoresis. J Mol Biol 1975;98:503-517.

19. Bronstein I. Rapid and sensitive detection of DNA in Southern blots with chemiluminescence. Biotechniques 1990;8:310-104.

20. Lohmann DR, Brandt B, Hopping W, Passarge E, Horsthemke $B$. The spectrum of RB1 germ-line mutations in hereditary retinoblastoma. Am J Hum Genet 1996;58:940-949. 
21. Munier FL, Thonney F, Balmer A, Heon E, Pescia G, Schorderet DF. Sex mutation ratio in retinoblastoma and retinoma: relevance to genetic counseling. Klin Monatsbl Augenheilkd 1996;208:400-403.

22. Vogel F. Genetics of retinoblastoma. Hum Genet 1979;52: $1-54$.

23. Dryja TP, Mukai S, Petersen R, Rapaport JM, Walton D, Yandell DW. Parental origin of mutations of the retinoblastoma gene. Nature 1989;15(339):556-558.

24. Schüler $A$, Weber $S$, Neuhäuser $M$, Jurklies $C$, Lehnert $T$, Heimann H, Rudolph G, Jöckel KH, Bornfeld N, Lohmann DR.
Age at diagnosis of isolated unilateral retinoblastoma does not distinguish patients with and without a constitutional RB1 gene mutation but is influenced by a parent-of-origin effect. Eur J Cancer 2005;41:735-740.

25. Zhu $X$, Dunn JM, Goddard AD, Squire JA, Becker A, Phillips RA, Gallie BL. Mechanisms of loss of heterozygosity in retinoblastoma. Cytogenet Cell Genet 1992;59:248-245.

26. Abramson DH, Mendelsohn ME, Servodidio CA, Tretter T, Gombos DS. Familial retinoblastoma: where and when? Acta Ophthalmol Scand 1998;76:334-338. 